\title{
Stability of antibodies and proteins in camel whey powder treated by Gamma-irradiation during radurisation process
}

\author{
Mohammad Ibrahim Ahmad ${ }^{1 *}$, Khaldoon Azmi Al-Qawasmeh², Shreen Deeb Nusair ${ }^{3}$, \\ Luay Fawzi Abu-Qatouseh ${ }^{4}$, Khaled Mahmoud Al-Qaoud ${ }^{5}$ \\ ${ }^{1}$ Research and Innovation Centre, The Jordanian Pharmaceutical Manufacturing Company, Amman, Jordan, ${ }^{2}$ Department of Biologicals, \\ Jordan Bio-Industry Centre, Amman, Jordan, ${ }^{3}$ Department of Clinical pharmacy, Faculty of pharmacy, Jordan University of Science and \\ Technology, Irbid, Jordan, ${ }^{4}$ Department of Pharmacology and Biomedical Sciences, Faculty of pharmacy, University of Petra, Amman, Jordan, \\ ${ }^{5}$ Department of Biological Science, Yarmouk University, Irbid, Jordan
}

\section{A B S T R A C T}

Camel milk and milk derived products have a growing potential in pharmacy, food and biotechnology industry. Its therapeutic value has been investigated and documented in many studies before. The contamination of camel whey powder during manufacturing and transportation may impact economy; re-pasteurisation could cause dramatic effect on antibodies and proteins of camel whey powder. Radurisation $(0.4$ to $10 \mathrm{kGy})$ process could be a choice in sterilising camel whey powder. This study aimed to investigate the stability of camel antibodies and proteins in whey powder before and after Gamma-irradiation. Efficacy of radiation dose on microbial content was also studied. Four batches of hyper immune camel whey powder containing antibodies against Propionibacterium acnes were subjected to six Gamma-radiation doses (1.5, 3, 4.5, 6, 7.5 and $9 \mathrm{kGy}$ ). Results revealed marked decline in the total microbial count (3-5 log cycles) after escalating the doses of irradiation. Minor effect on antibody activity ( $7.4 \%$ reduction) was observed after treating the whey by $9 \mathrm{kGy}$. Moreover, the concentration of total camel IgG was reduced by $13 \%$ using the same irradiation dose. In addition, no effect on major whey proteins (Lactoferrin, Casein, and $\alpha$-lactoalbumin) was revealed in protein identification using SDS-PAGE. In conclusion, using $9 \mathrm{kGy}$ dose of Gamma-irradiation for sterilising camel whey powder is effectively reducing bacterial contamination with limited effects on antibodies activity and protein stability.

Keywords: Camels; Antibodies; Whey; Gamma-irradiation; Stability

\section{INTRODUCTION}

Total milk production was estimated at 466 million metric tons (mt) in 2013 (Lagrange et al., 2015); it is a major segment of protein industry all over the world. Whey derived from ruminant milk like cattle, sheep, goats and camels has been used in food industry as a source of proteins. Whey has been shown to be superior to other protein sources in stimulating and improving muscle protein synthesis (MPS) under both rested and post-exercise conditions (Litwin et al., 2015). Moreover, bovine whey has been used in infant and follow-on baby formula to mimic breast milk and to provide all the nutritional requirements for the growing babies (Lagrange et al., 2015). Previous studies have reported benefits of using whey proteins for muscle mass gain, particularly, in sarcopenia (i.e., decline of skeletal muscle with age) (Verlaan et al., 2014).

In biotechnology, the claim is not only for the protein content of the whey, but also for its therapeutic antiinflammatory proteins and immunoglobulins. For example milk lactoferrin has shown many protective and therapeutic characteristics like; ability to relieve cold symptoms in participants with the common cold, reduction of proliferation of cancer cells and protection against hepatitis virus (EsmailM et al., 2008; Habib et al., 2013; Vitetta et al., 2013). Immunoglobulin, a major components of milk and whey, showed some therapeutic and prophylactic characteristics against pathogenic and poisonous substances (Nusair and Tay, 2009; Yagil, 2013).

\footnotetext{
${ }^{*}$ Corresponding author:

Mohammad Ibrahim Ahmad, Research and Innovation Centre, The Jordanian Pharmaceutical Manufacturing Company (PLC), Naor 11710, Jordan. Tel: +962 6 4290744. Fax: +962 6 4290752. E-mail: m.malkawy@jpm.com.jo
}

Received: 28 January 2018; $\quad$ Accepted: 01 July 2018 
The rising global demand for industrial whey production using the high cost technology of ultra-filtration and microfiltration has declined the chances for associated bacterial and fungal contamination. On the other hand, contamination during subsequent processing, or transportation is likely to occur and may cause huge economic losses. Therefore, the need for the afterprocessing sterilisation is crucial to keep the microbial numbers within the defined limits of global guidelines and regulations. Gamma-irradiation, as a low-cost method for sterilisation, has been used before to sterilise whey powder (Ababneh et al., 2010; Kaddouri et al., 2008; Osaili et al., 2008). The essence of gamma-irradiation sterilisation is to damage the microbial DNA. Radurisation is a process used to improve the shelf-life and quality characteristics of a product by employing doses of $0.4 \mathrm{kGy}$ to $10 \mathrm{kGy}$. The process of food irradiation by Gamma has been required by many countries' legislations and has been used in many food products available in global markets (Griffiths, 2010).

Camel dairy products have a growing market, as well as satisfying competencies among other ruminant dairy products (Table 1) (Ipsen, 2017). All camelids antibodies demonstrate unique characters other than conventional antibodies; the Heavy Chain Antibodies (HCAbs) lack the light chains and the first heavy constant domains. Nanobodies derived from camel's heavy chain variable region (VHH) showed good solubility and stability characteristics and remained functionally active, even after being exposed to harsh conditions, such as heat and $\mathrm{pH}$ variations (Muyldermans et al., 2009). These antibodies pass to camel milk during lactation period. In general, camel milk has high levels of unsaturated fatty acids, has anti-cancer, hypo-allergic and anti-diabetic properties (Badr, 2013). The hypo-allergic effect of camel milk has been linked to the low quantity of $\beta$-casein and the lack of $\beta$-lactoglobulin protein. Other components such as lactoferrin, immunoglobulin, lysozyme, and vitamin $C$ were reported to contribute to these properties (Konuspayeva et al., 2007; Mati et al., 2017).

In this context, this study aims to evaluate the effect of gamma-irradiation on antibodies activity, protein stability,

Table 1: Multiple commercial products based on camel milk and whey and their origin

\begin{tabular}{|c|c|c|c|c|}
\hline Product & Manufacturer & Origin & Active ingredient & Website \\
\hline Al-nassma Chocolate & AI Nassma Choocolate LIC & UAE & Camcl Milk & htpp//www.al-nassma.com \\
\hline Brighten skin & Shea Terra Organics & USA & Camel Milk & http//www.sheaterraorganics.com \\
\hline Skinue Cosmetics & Monojo & Jordan & Camel Whey & htrpy/hwww.skinuenest \\
\hline Camel Milk Soap & Desen Farm & USA & Camel Whey & http:/desenfirms.con \\
\hline Ise Cream & Al Ain Dairy Farm & UAE & Camcl Milk & httpr//uwww:alaindairycom \\
\hline $\begin{array}{l}\text { Camelicious Camel milk } \\
\text { whey powder }\end{array}$ & Camelicious & UAE & Camel Whey & 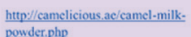 \\
\hline
\end{tabular}

Emir. J. Food Agric • Vol $30 \bullet$ Issue 8 • 2018 and microbial contamination in camel whey powder. The study also demonstrates potential implications in associated dairy industries.

\section{MATERIALS AND METHODS}

\section{Experimental design}

A total amount of 12 Litres of camel milk enriched with antibodies against Propionibacterium acnes (NCTC 737) were separately collected from four different immunised female camels, lipids were removed by centrifugation at $15,600 \mathrm{xg} / 0^{\circ} \mathrm{C}$ for one hour (Hermile, Germany). The skimmed milk was then warmed to $37^{\circ} \mathrm{C}$, and $100 \mathrm{mg} / \mathrm{L}$ of Rennet (valiren, USA) was added for de-caseination. The formed whey was lyophilized (zirbus freeze dryer, Germany); the resultant powder was then designated as Batch 1, Batch 2, Batch 3 and Batch 4. The batches were stored separately in sterile plastic bottles. Batches 1-3 were used for the microbial analysis before and after multiple irradiation doses $(0,1.5,3,4.5,6,7.5$ and $9 \mathrm{kGy})$.

Batch 4, which was collected from camel with high titre of antibodies against P. acnes (Ahmad et al., 2016; Al-Qaoud et al., 2014), was used for detecting antibodies activity and protein stability after one dose of $9 \mathrm{kGy}$. Batch 1-3 were divided into seven treatments ( 3 bottles per treatment; $16.5 \mathrm{~g}$ per bottle) as follows: Control 1 (exposed to $0 \mathrm{kGy}$ ); Group 1 (exposed to $1.5 \mathrm{kGy}$ ); Group 2 (exposed to $3.0 \mathrm{kGy}$ ); Group 3 (exposed to $4.5 \mathrm{kGy}$ ); Group 4 (exposed to $6.0 \mathrm{kGy}$ ); Group 5 (exposed to $7.5 \mathrm{kGy}$ ); and Group 6 (exposed to $9.0 \mathrm{kGy}$ ). Batch No.4, which was used for the activity study, was divided into two samples as follows: Group A (exposed to $0 \mathrm{kGy}$ ); and Group B (exposed to $9.0 \mathrm{kGy}$ ).

\section{Gamma irradiation}

The irradiation process was carried out at the irradiation facility located in the Jordan Atomic Energy Agency (JAEA) (Amman, Jordan) following the protocol described in (Azzeh and Amr, 2009). Samples of batches 1-3 were irradiated at $1.5 ; 3.0 ; 4.5 ; 6.0 ; 7.5$; and $9.0 \mathrm{kGy}$ in the gamma cell (gamma facility PX-g-30 irradiator model, Russia) at room temperature, in the presence of air. Irradiation treatment was performed at a dose rate of $45 \mathrm{~Gy} / \mathrm{min}$; using a 60-Cobalt source. Group B of Batch 4 was irradiated at $9.0 \mathrm{kGy}$. After irradiation all samples were stored at $-20{ }^{\circ} \mathrm{C}$ for further analysis.

\section{Bacteriological analysis}

Recovery of potential contamination microorganisms was performed by the standard plate count method. In brief, 1:10 dilution of each treatment was prepared in a total volume of $10 \mathrm{ml}$ of sterile D.H2O. Then $0.1 \mathrm{ml}$ was spread on the surface of Tryptone Soy Agar (Oxoid, UK) 
plates which were subsequently incubated at $37^{\circ} \mathrm{C}$ for 48 hours. Samples were inoculated in duplicates and the mean of the total count of each treatment was calculated. Three $\log$ reduction in bacterial counts in each treatment was considered significant.

\section{Measurement of IgG antibody activity in camel whey before and after irradiation}

Camel polyclonal antibodies against $P$. acnes (NCTC 737) were measured using indirect Enzyme Linked Immunosorbent Assay (ELISA) as described previously (Ahmad et al., 2016). Briefly, $5.0 \mu \mathrm{g}$ of bacteria OMPs were suspended in $1.0 \mathrm{ml}$ carbonate/bicarbonate solution ( $\mathrm{pH}$ 9.6). Subsequently, $0.1 \mathrm{ml}$ of the suspension was added per well in a 96-well flat-bottom ELISA plate (Greiner, Germany). The plate was covered and incubated overnight at $4^{\circ} \mathrm{C}$. On the next day, wells were washed with $0.15 \mathrm{M}$ PBS containing $0.05 \%$ Tween-20. A blocking buffer was prepared by mixing $2.0 \%$ bovine serum albumin (BSA) in $0.15 \mathrm{M}$ PBS. A $0.2 \mathrm{ml}$ aliquot of this blocking buffer was added per well. The plate was incubated overnight at $4^{\circ} \mathrm{C}$. Later, the wells were washed twice using $0.15 \mathrm{M}$ PBS containing $0.05 \%$ Tween-20.

Whey samples $30 \mathrm{mg} / \mathrm{ml}$ of Batch 4 were prepared in a sterile PBS. Antibodies in whey samples were measured at a dilution of $1 / 50$ in $1.0 \%$ BSA/PBS. Samples were processed in duplicates. A $0.1 \mathrm{ml}$ of the diluted whey samples were added per well and incubated for 1 hour at room temperature. After washing, $0.1 \mathrm{ml}$ of the purified mouse anti-camel IgGs HRP Abs; previously prepared in-house (Ahmad et al., 2016; Khaled et al., 2014), at a dilution of 1:500 in 1\% BSA/PBS, was added to each well. Then, the plate was incubated with shaking for one hour at room temperature. After washing the plate with PBS-T, $1 \mathrm{mg} / \mathrm{ml}$ O-phenylenediamine (OPD, Acros organics, USA) was prepared in citrate buffer at $\mathrm{pH} 4.5$. A $0.1 \mathrm{ml}$ of OPD containing hydrogen peroxide was added to each well, and the plate was incubated for 5 minutes at room temperature. Finally, the plate was read at $450 \mathrm{~nm}$ using ELISA reader (Thermo Scientific, Finland). Activity Percent was calculated using following formula:

$$
\text { ActivityPercent }=\frac{\text { O.D sample }}{\text { O.D sample before irradiation }} * 100 \%
$$

Measurement of total antibody IgG concentration (stability and degradation) in camel whey before and after irradiation

Camel total antibodies IgG concentration was measured using Competitive Enzyme Linked Immunosorbent Assay. Briefly, $5 \mu \mathrm{g}$ of camel IgG (Prepared in house) were suspended in $1.0 \mathrm{ml}$ carbonate/bicarbonate solution ( $\mathrm{pH}$ 9.6). Subsequently, $0.1 \mathrm{ml}$ of the suspension was added to each well of the 96-well flat-bottom ELISA plate
(Greiner, Germany). The plate was covered and incubated overnight at $4^{\circ} \mathrm{C}$. On the next day, wells were washed with $0.15 \mathrm{M}$ PBS containing $0.05 \%$ Tween-20. Blocking buffer was prepared by mixing $2 \%$ bovine serum albumin (BSA) in 0.15 M PBS. A $0.2 \mathrm{ml}$ aliquot of the blocking buffer was added to each well. The plate was incubated overnight at $4^{\circ} \mathrm{C}$. Wells were washed twice using $0.15 \mathrm{M}$ PBS containing $0.05 \%$ Tween-20. Standard camel IgG with known concentration was serially diluted and added to wells in duplicate. Whey samples were prepared in $30 \mathrm{mg} / \mathrm{ml}$ total protein. Antibodies in whey samples were measured at a dilution of 1/50 in 1\% BSA/PBS. Samples were processed in duplicates. The plate was incubated with $0.1 \mathrm{ml}$ of diluted whey samples and $0.1 \mathrm{ml}$ of conjugated mouse anti-camel HRP (1:2000) in PBS/BSA (Prepared in house). Samples were stored for 2 hours at room temperatures. After Washing with PBS-T, $0.1 \mathrm{ml}$ of OPD substrate containing hydrogen peroxide was added to each well, and the plate was incubated for 20 minutes at room temperature. Finally, the plate was stopped by adding $0.05 \mathrm{ml}$ of $3 \mathrm{M} \mathrm{HCl}$. Then the plate was read at 492nm using ELISA reader (Thermo Scientific, Finland). Final absorbance of samples was plotted against camel $\operatorname{IgG}$ standard curve with known concentration.

\section{Assessment of whey antibodies and proteins}

SDS-PAGE was used to determine the profile and the purity of antibodies and proteins of whey samples before and after irradiation. The samples were prepared in $30 \mathrm{mg} / \mathrm{ml}$ in distilled water, then diluted 1:1 and loaded into a 12.5\% running gel with $4.0 \%$ polyacrylamide stacking gel using a Bio-Rad Mini-PROTEAN 2 system (Bio-Rad Laboratories, USA). All samples were compared to a positive sample of anti-acne camel whey. The gel was stained with $0.2 \%$ Coomassie Brilliant Blue R-250 solution. The stained gel was then washed with a mixture of acetic acid: water (1:5) to examine the resulted bands.

\section{RESULTS AND DISCUSSION}

\section{Total bacterial count}

Total bacterial count has markedly declined after gammairradiation treatment in all batches. The total bacterial count of Batch 1 was successfully reduced $3 \log$ cycles. The decline was proportionally increased as the radiation dose increased (Fig. 1). Batches 2 and 3 showed significant decrease after multiple doses of irradiation. 5 log cycles reduction was observed in Batch 2 and 3 at $9.0 \mathrm{kGy}$ dose.

Gamma-irradiation caused a significant decrease in microbial count on camel whey powder. This is due to the effect of the Gamma ray on the DNA of the microorganisms. It is plausible that the gamma- 


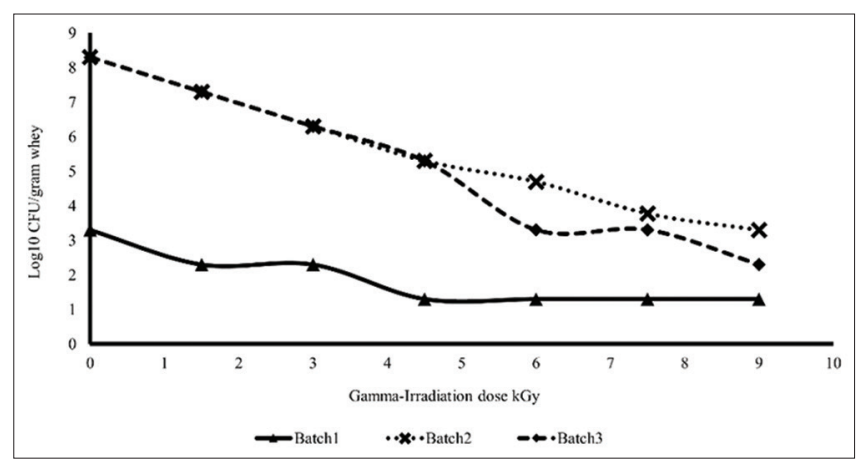

Fig 1. Colony total bacterial count (Log10) of camel whey powder from three different batches (1, 2 and 3 ). Control sample received no irradiation. Other testing samples treated by different irradiation doses.

irradiation of the Cobalt- 60 induced DNA damage through the generated energy of 1.17 and $1.33 \mathrm{MeV}$; that could have produced a cascade of secondary electrons. The resulted free electrons have catalysed the formation of free radicals, which are reported to damage microbial DNA. Variation in the bacterial count of the treated batches may be explained by the variation of the initial bacterial load of the batches before radiation. Further, health status of the udder such as subclinical mastitis could have contributed to the variation of the bacterial load of the samples.

In agreement with our results, de Oliveira Silva et al (2015), reported a significant decrease in the bacterial load by two to three log cycles in milk samples exposed to irradiation doses of 1, 2 and $3 \mathrm{kGy}$ doses, compared to the nonirradiated control sample (de Oliveira Silva et al., 2015).

\section{Antibodies activity}

Ability of camel antibodies to neutralise and capture P. acne antigens was determined using the anti-P. acne antibodies assay. The results revealed minor effect on the camel antibodies activity; $9 \%$ of the activity was reduced after irradiation. Total IgG assay, using competitive ELISA, indicated a $13 \%$ degradation of the camel $\operatorname{IgG}$ after treating with $9 \mathrm{kGy}$ (Fig. 2).

The activity of antibodies is attributed to the activity of the antibodies binding site, which is the $\mathrm{VHH}$ region and the constant heavy chain part of dromedary antibodies. In general, camel antibodies withstand harsh conditions, such as high temperatures during pasteurisation $\left(65^{\circ} \mathrm{C} / 30 \mathrm{~min}\right)$ and $\mathrm{pH}$ variations during purification processes (Chen et al., 2016). The $9 \%$ decrease of the activity could have been due to protein denaturation caused by gamma ray; the formation of free radicals; and the generation of the kinetic energy on the paratops of the conventional isotype ( $\operatorname{IgG} 1)$ of camel antibodies. These results are in harmony with the results of the total camel $\operatorname{IgG}$ assay; it revealed a decrease

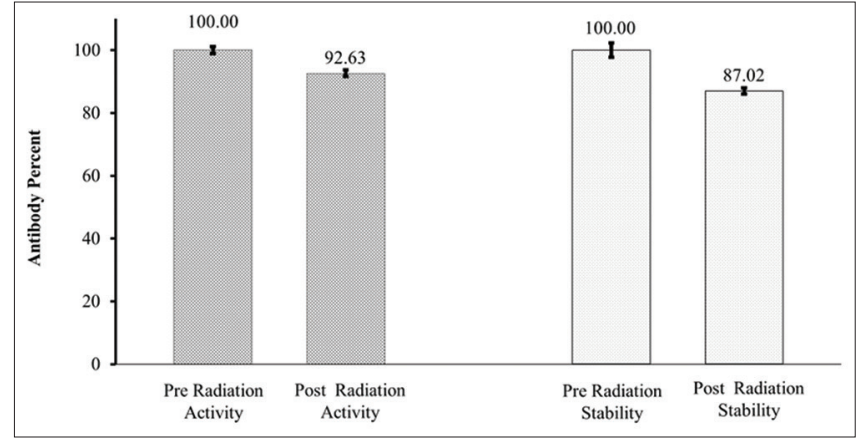

Fig 2. Percent activity and stability of anti- $P$. acne antibodies (total $\operatorname{lgG}$ ) in camel whey (1:50) before and after treatment of 9 kGy dose as per ELISA. Activity percent was calculated using following formula: Activity $\%=\frac{\text { O.D sample }}{\text { O.D sample before irradiation }} * 100 \%$

Stability (total lgG) was calculated by plotting samples before and after irradiation against camel IgG standard curve. Then the percent of loss in total IgG was calculated using the following formula:

$\left(\begin{array}{l}\text { Total Amount of } \lg G \text { Before Irradiation - } \\ \frac{\text { TotalAmount of } \lg G \text { After Irradiation }}{\text { TotalAmount of } \lg G \text { Before Irradiation }}\end{array}\right) * 100 \%$

Each bar corresponds to the mean value of duplicate measure and the error bars represent the mean \pm SEM.

of $13 \%$ in the total camel $\operatorname{IgG}$. The decrease reflects the degradation of camel $\operatorname{IgG}$ which is not essential to affect the activity of camel antibodies. Camel antibodies are very stable and could maintain activity even after degradation. This was reported in the VHH region of camel antibodies, also known as Nanobodies (Könning et al., 2017; Muyldermans, 2013). Another explanation for the loss of the antibodies activity could be explained by a study conducted by Dumoulin et al. to investigate the stability and activity of camel HCAb single domain antigen binders implementing both chemical and thermal denaturation conditions. The results of the study showed complete recovery of the biological activities of the camel derived $\mathrm{HCAb}$ after exposure to chemical induced denaturation factors. However, thermal induced denaturation of the $\mathrm{HCAb}$ caused minor effect on the biological activities of the antibodies. The authors attributed the stability of the functional activity of the HCAb to the unfolding/refolding equilibrium that conserve the thermodynamic stability of the binding site in the antibody (Dumoulin et al., 2002). The decrease of antibodies activity and stability in our study could be attributed to minor loss in the refolding ability of the HCAb.

\section{Sds-page}

Major bands in the SDS-PAGE gel denote equal density of whey proteins; lactoferrin, Albumin, $\alpha$-lactoalbumin, IgG1 and heavy chain antibodies before and after irradiation at all radiation doses (Fig. 3). 


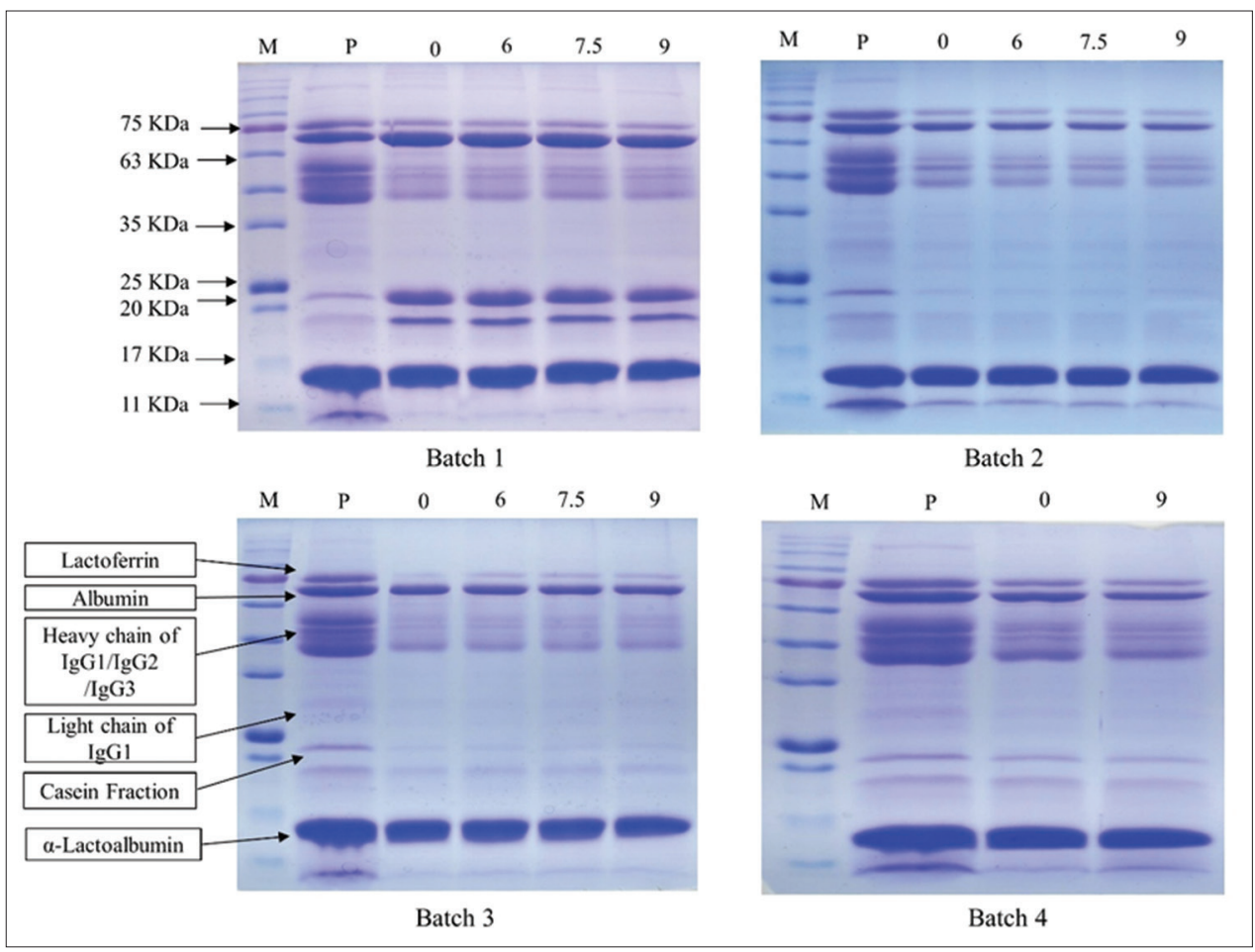

Fig 3. SDS-PAGE profile of camel whey from all batches (1-4) before and after different doses of irradiation. (M) denotes for SDS protein marker, $(P)$ denotes for Positive anti- $P$. acne camel whey $(30 \mathrm{mg} / \mathrm{ml}),(0)$ denotes for whey before treatment, (6) denotes for whey after treatment of $6 \mathrm{kGy}$, (7.5) denotes for whey after treatment of $7.5 \mathrm{kGy}$, (9) denotes for whey after treatment of $9 \mathrm{kGy}$.

\section{CONCLUSION}

Gamma-irradiation has insignificant effect on the activity and the stability of camel whey powder proteins and antibodies. Thus, gamma-irradiation could be used in radurisation and decontamination of camel whey powder during manufacturing and transportation. Further studies are recommended to focus on the effect of gamma irradiation on camel antibodies complement fixation ability and other immunological properties. Studies also are recommended on activity of antimicrobial proteins like lactoferrin in camel whey.

\section{ACKNOWLEDGEMENTS}

The authors here are grateful to Jordan Company for antibody Production and to the Jordan Atomic Energy Agency (JAEA) (Amman, Jordan) and to the cooperation of the Engineer Mohammad Al-Otoom.

\section{COMPETING INTERESTS}

The Authors declare that there is no conflict of interest.

\section{Authors' contributions}

All the listed authors had participated in the manuscript. Mohammad I. Ahmad did all the animal field work and part of the lab experiments, he also wrote the draft of the manuscript; Khaldoon A Al Qwasmeh did part of the lab experiments; Shreen D Nusair helped in the interpretation of data and proof reading of the final copy. Luay F AbuQatouseh helped in designing of study and revising of the manuscript and Khaled M. Al-Qaoud helped in designing the study and did the proof reading of the final copy of the manuscript.

\section{REFERENCES}

Ababneh, Z.Q., A. M. Alyassin, K. M. Aljarrah, and A. M. Ababneh. (2010). Measurement of natural and artificial radioactivity in powdered milk consumed in Jordan and estimates of the corresponding annual effective dose. Radiat. Prot. Dosimetry. 138: $278-283$.

Ahmad, M., H. Issa, S. Yousef, P. Shihab and K. Al-Qaoud. (2016). The role of adjuvant on safety and antibody modulation of dromedary camel. J. Camel Pract. Res. 23: 65-72.

Al-Qaoud, K.M., P. A. Shihab, L. F. Abu-Qatouseh and C. R. Lowe. (2014). Camel Milk-Based Topical Pharmaceutical Composition, Google Patents.

Azzeh, F. S. and A. S. Amr. (2009). Evaluation of protein content, lysine and sulfur-containing amino acids content and electrophoretic patterns of soluble proteins for gamma-irradiated semolina before and after milling of durum wheat. Radiat. Phys. Chem. 78: 971-975.

Badr, G. (2013). Camel whey protein enhances diabetic wound healing in a streptozotocin-induced diabetic mouse model: The critical role of $\beta$-Defensin-1,-2 and-3. Lipids Health Dis. 12: 46.

Chen J., Q. H. He, Y. Xu, J. Fu, Y. P. Li, Z. Tu, D. Wang, M. Shu, 
Y. I. Qiu, H. W. Yang and Y. Y. Liu. (2016). Nanobody medicated immunoassay for ultrasensitive detection of cancer biomarker alpha-fetoprotein. Talanta. 147: 523-530.

de Oliveira Silva A.C., L. A. T. de Oliveira, E. F. O. de Jesus, M. A. S. Cortez, C. C. C. Alves, M. L. G. Monteiro and C. N. Conte Junior. (2015). Effect of gamma irradiation on the bacteriological and sensory analysis of raw whole milk under refrigeration. J. Food Proc. Preserv. 36: 12490.

Dumoulin M., K. Conrath, A. Van Meirhaeghe, F. Meersman, K. Heremans, L. G. J. Frenken, S. Muyldermans, L. Wyns and A. Matagne. (2002). Single-domain antibody fragments with high conformational stability. Protein Sci. 11: 500-515.

Esmail M, E. F. , T. Ashraf, W. A. El, M. H. Bakry and M. R. El-Rashdy. (2008). Potential activity of camel milk-amylase and lactoferrin against hepatitis c virus infectivity in HepG2 and lymphocytes. Hepat. Mon. 2008: 101-109.

Griffiths, M. (2010). Improving the Safety and Quality of Milk: Improving quality in milk Products. Amsterdam: Elsevier.

Habib, H.M., W. H. Ibrahim, R. Schneider-Stock and H. M. Hassan. (2013). Camel milk lactoferrin reduces the proliferation of colorectal cancer cells and exerts antioxidant and DNA damage inhibitory activities. Food Chem. 141: 148-152.

Ipsen, R. (2017). Opportunities for producing dairy products from camel milk: A comparison with bovine milk. Food Chem. 11: 6.

Kaddouri, H., S. Mimoun, K. E. El-Mecherfi, A. Chekroun, O. Kheroua and D. Saidi. (2008). Impact of \&\#945;-Radiation on antigenic properties of cow's milk \&\#946;-Lactoglobulin. J. Food Protect. 71: 1270-1272.

Khaled, A. Q., Y. Sana, R. Abdulrahman, K. Raida and A. H. Sami. (2014). Blocking of histamine release and IgE binding to FcERI on human basophils by antibodies produced in camels. Allergy Asthma Immunol Res. 7.

Könning, D., S. Zielonka, J. Grzeschik., M. Empting, B. Valldorf, S. Krah, C .Schröter, C. Sellmann, B. Hock and H. Kolmar. (2017). Camelid and shark single domain antibodies: structural features and therapeutic potential. Curr. Opin. Struct. Biol. 45: 10-16.

Konuspayeva, G., B. Faye, G. Loiseau and D. Levieux. (2007). lactoferrin and immunoglobulin contents in camel's milk (Camelus bactrianus, Camelus dromedarius, and Hybrids) from Kazakhstan. J Dairy Sci. 90: 38-46.

Lagrange, V., D. Whitsett and C. Burris. (2015). Global market for dairy proteins. J. Food. Sci. 80: A16-A22.

Litwin, N. S., B. H. R. Bradley and G. D. Miller. (2015) Dairy proteins in nutrition and food science: Functional ingredients in the current global marketplace. J.Food Sci. 80: A1-A1.

Mati, A., C. Senoussi-Ghezali, S. Si Ahmed Zennia, D. Almi-Sebbane, H. El-Hatmi and J. M. Girardet. (2017). Dromedary camel milk proteins, a source of peptides having biological activities-a review. Int. Dairy J. 73: 25-37.

Muyldermans, S. (2013). Nanobodies: Natural single-domain antibodies. Ann. Rev. Biochem. 82: 775-797.

Nusair S and G. Tay. (2009) Production of polyclonal antibodies in milk for protection against deltamethrin poisoning. Internet $\mathrm{J}$. Lab. Med.2009: 4.

Osaili, T., A. Al-Nabulsi, R. Shaker, M. Ayyash, A. Olaimat, A. Abu Al-Hasan, K. Kadora and R. Holley. (2008) Effect of environmental stresses on the sensitivity of Enterobacter sakazakii in powdered infant milk formula to gamma radiation. Lett. Appl. Microbiol. 47: 79-84.

Verlaan, S., J. Bauer, C. Sieber and T. Cederholm. (2014). O4. 10: Muscle mass, strength, and function effects of a high-whey, leucine-enriched nutritional intervention in sarcopenic elderly in a double blind, randomised controlled trial. Eur. Geriatr. Med. 20: $S 75$.

Vitetta, L., S. Coulson, S. L. Beck, H. Gramotnev, S. Du and S. Lewis. (2013) The clinical efficacy of a bovine lactoferrin/whey protein Ig-rich fraction $(\mathrm{Lf} / \mathrm{lgF})$ for the common cold: A double blind randomized study. Complementary Ther. Med. 21: 164-171.

Yagil, R. (2013). Camel milk and its unique anti-diarrheal properties. Israel Med. Assoc. J. 15: 35-36. 